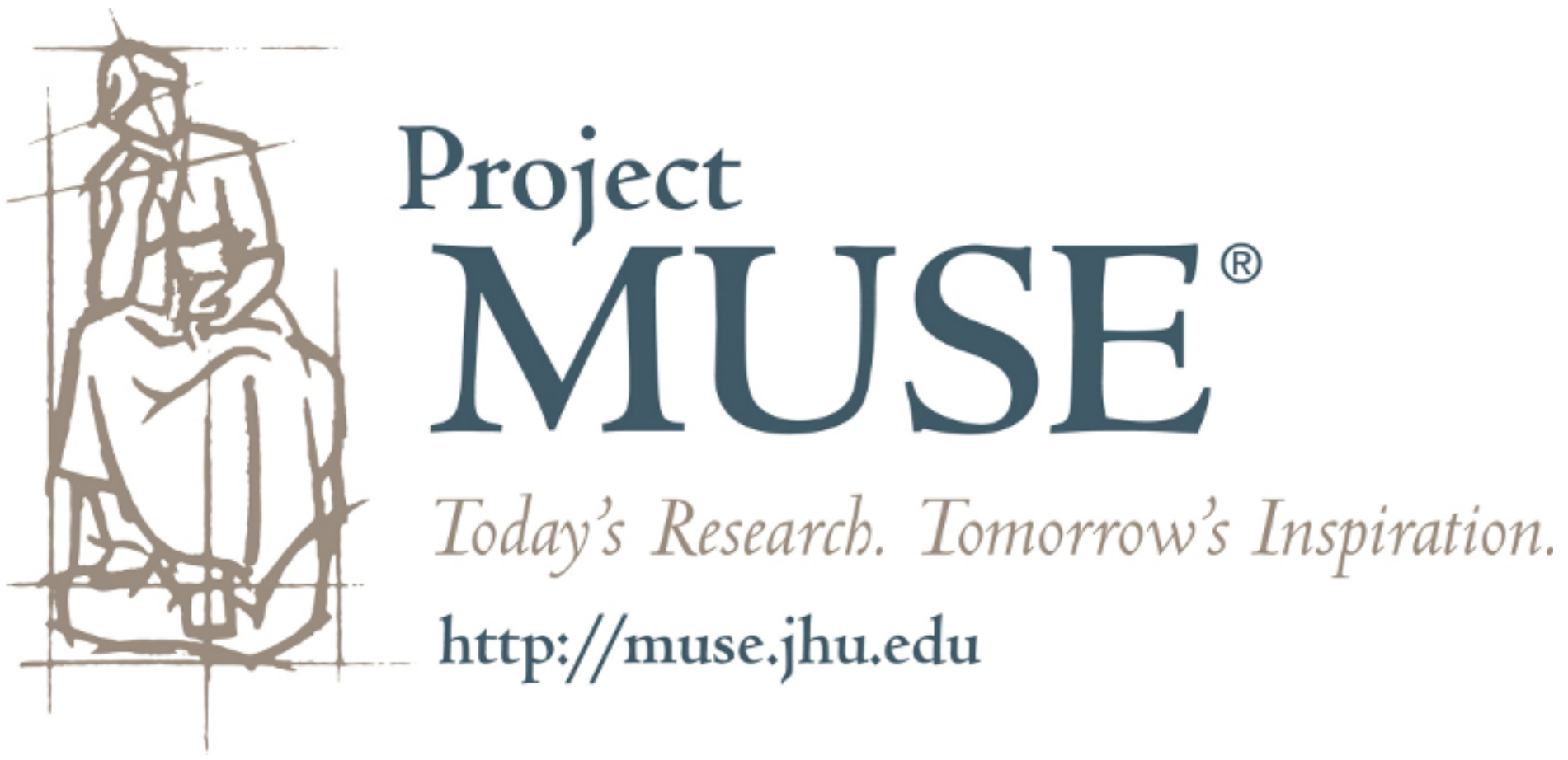




\section{A TASTE FOR THE BEAUTIFUL}

Hollis Taylor, 57-B Chaseling Avenue, Springwood, NSW, 2777, Australia.

E-mail: <hollistaylor@me.com>.

\section{Abstract}

Bowerbirds are named for the structures they build, paint, and decorate. This photo essay documents the efforts of three species of Australian bowerbirds.

The influence of sexual selection is pertinent, as the female bowerbird performs her concomitant function as art critic.

See $<$ www.mitpressjournals.org/toc/leon/44/3> for supplemental files related to this article. Submitted: 5 December 2009

In 1871, Charles Darwin credited birds "with strong affections, acute perception, and a taste for the beautiful" [1]. My work in Australia involves video and audio documentation of such birds. For example, bowerbirds, which live in Australia and Papua New Guinea, are named for the architecturally complex and varied stick structures that they build. Bowers are decorated with fruits, flowers, seedpods, feathers, bones, skulls, stones, shells, insects, resins, fungi, lichens, ferns, leaves, charcoal, and other natural, as well as man-made, objects.

Color preferences influence those items used for bower decoration. Satin bowerbirds (Ptilonorhynchus violaceus) favor blue, with a secondary preference for yellow, while great (Chlamydera nuchali) and western bowerbirds (Chlamydera guttata) choose white and green. Bowerbird preferences run to more than tint - saturation, shape, size, texture, luminescence, sheen - these may factor into the choices the bird makes when assembling his collection.

Males accumulate decorations as a kind of wealth, and there is speculation that enjoyment is involved, as males are known to perform decoration and courtship behavior in the absence of any audience [2]. Fading vegetable matter and decorative items robbed by competitors are regularly replaced [3].

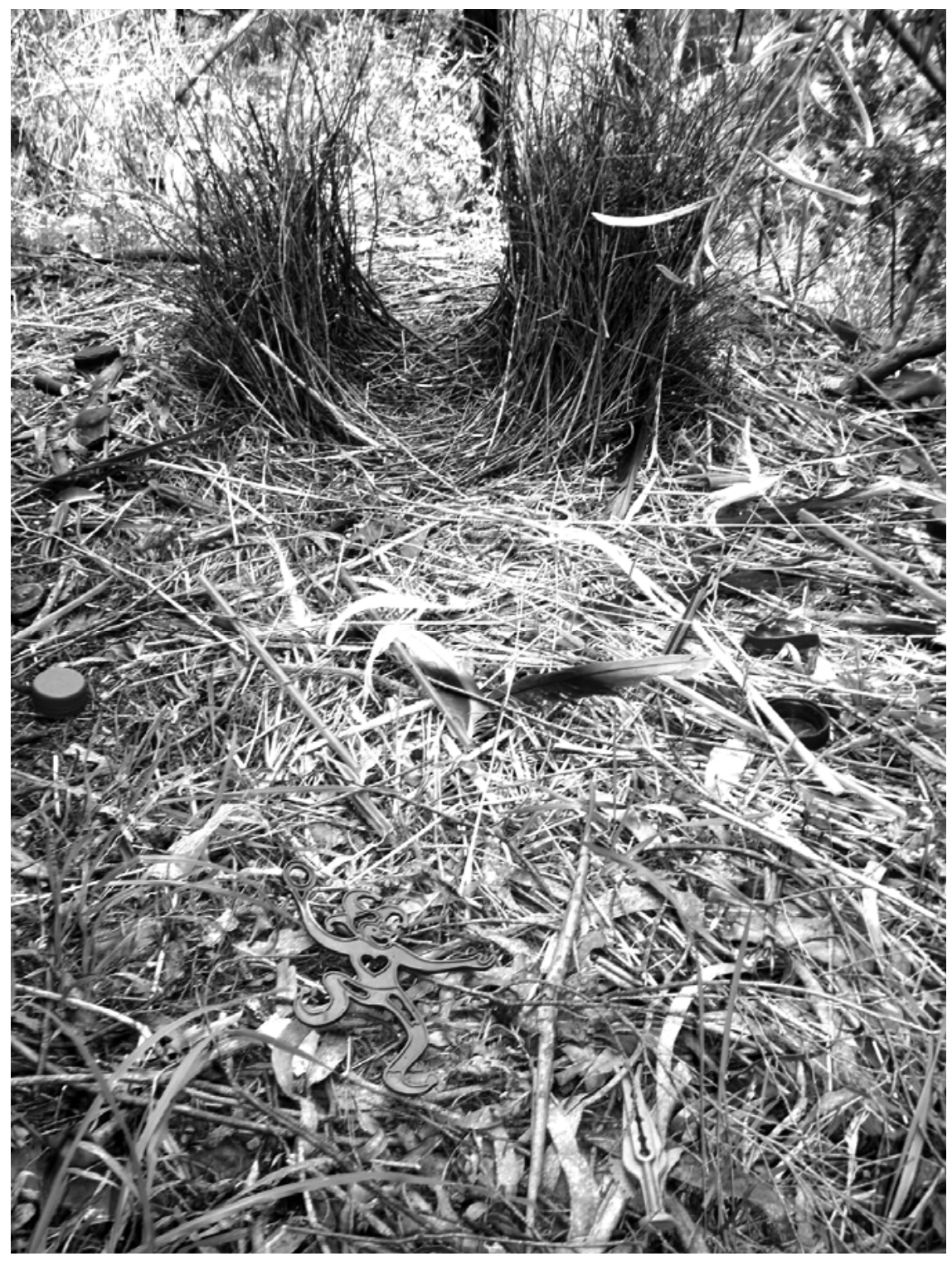

Fig. 1. This avenue bower is not a nest-it serves as a backdrop to the stage where a male satin bowerbird would sing and perform a ritualized dance to attract a female, and where they would mate if he were successful. (Photo $@$ Hollis Taylor.)

Fig. 2. Plastic has been a boon to satin bowerbirds. This one chooses human artifacts almost exclusively for his decorations. (Photos $($ C Hollis Taylor.)

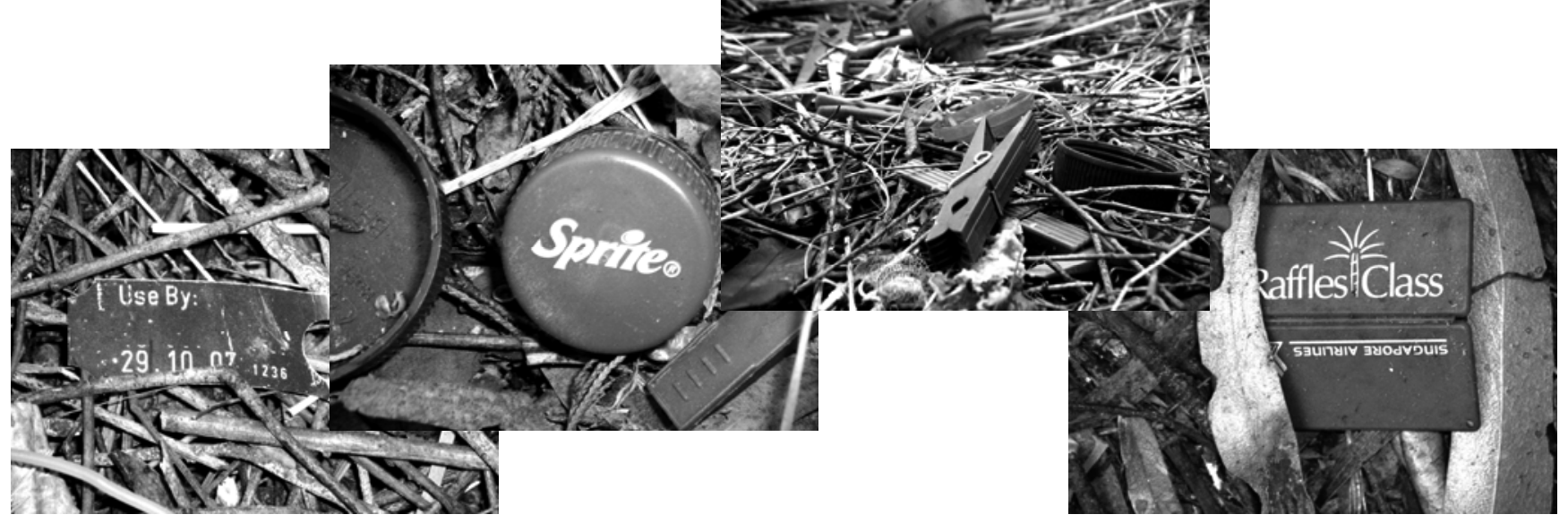



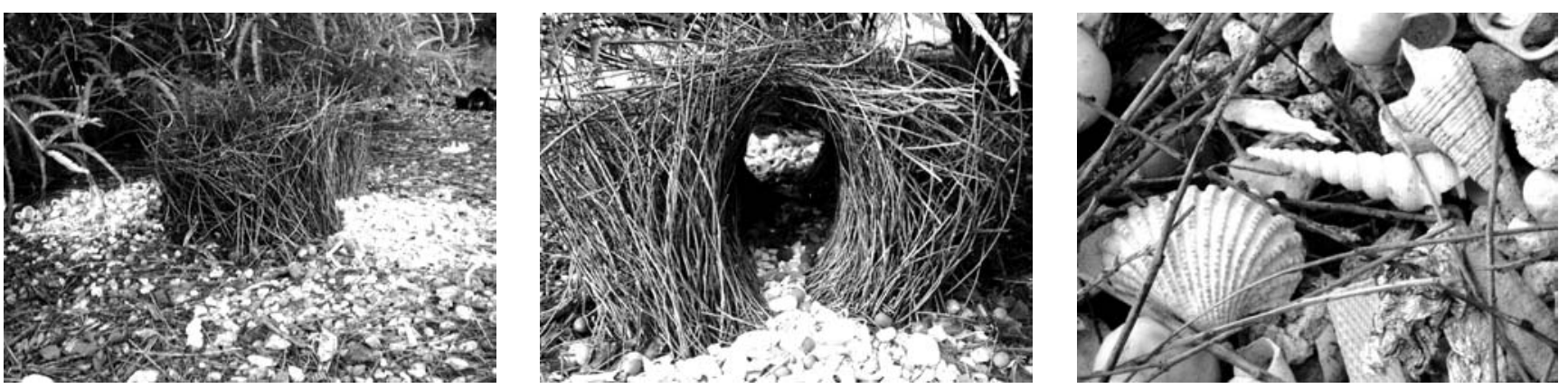

Fig. 3. Great bowerbirds prefer things green and white, as three views (above) of this collection of white shells and stones mixed with green seedpods and fruits exemplify. However, green and white are not the only criteria- they collect objects with reflective surfaces, like glass, plastic cups, metal objects, and aluminum foil (below). (Photos $@$ C Hollis Taylor)
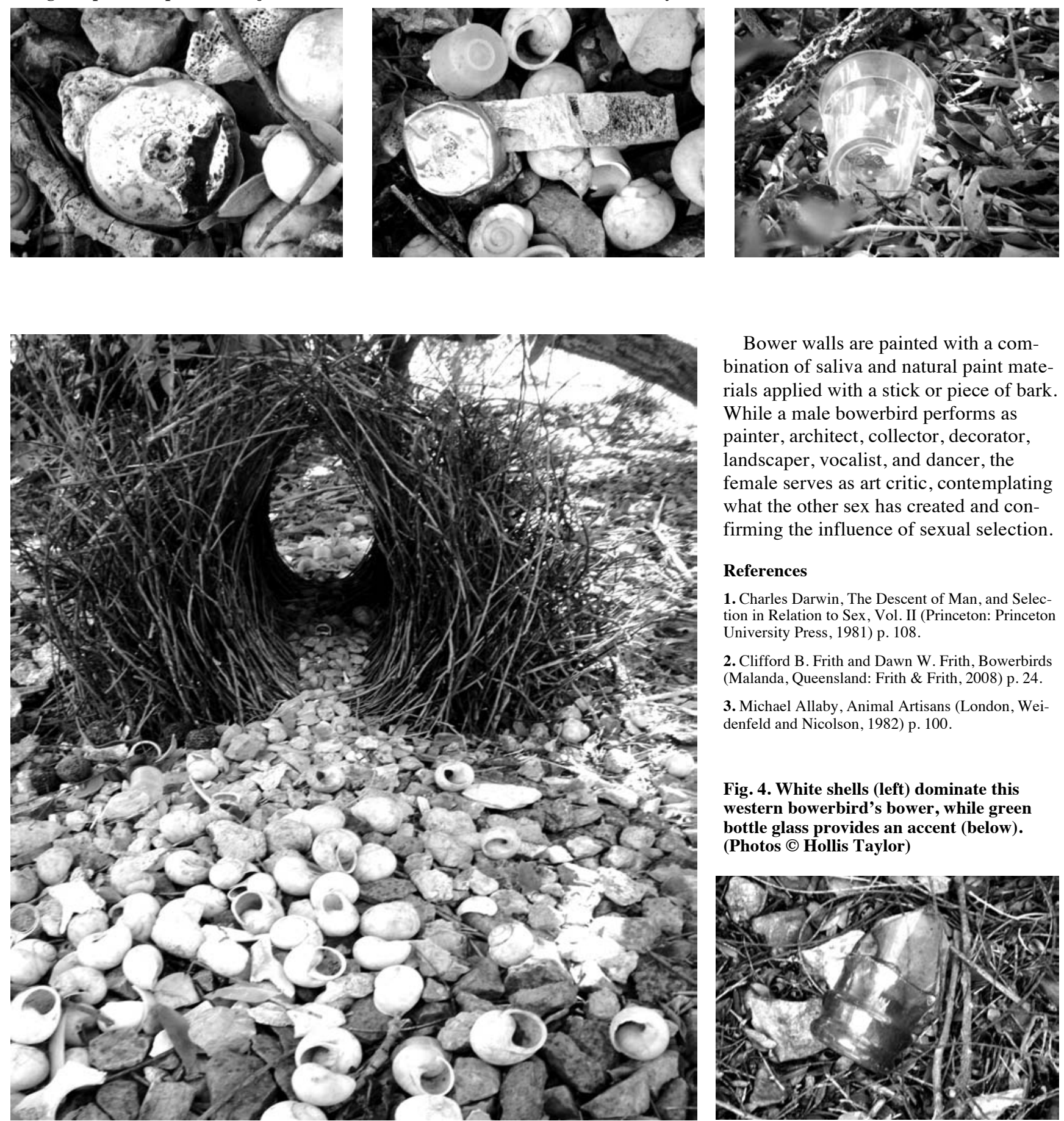

Bower walls are painted with a combination of saliva and natural paint materials applied with a stick or piece of bark. While a male bowerbird performs as painter, architect, collector, decorator, landscaper, vocalist, and dancer, the female serves as art critic, contemplating what the other sex has created and confirming the influence of sexual selection.

\section{References}

1. Charles Darwin, The Descent of Man, and Selection in Relation to Sex, Vol. II (Princeton: Princeton University Press, 1981) p. 108

2. Clifford B. Frith and Dawn W. Frith, Bowerbird (Malanda, Queensland: Frith \& Frith, 2008) p. 24.

3. Michael Allaby, Animal Artisans (London, Weidenfeld and Nicolson, 1982) p. 100.

Fig. 4. White shells (left) dominate this western bowerbird's bower, while green bottle glass provides an accent (below). (Photos $\odot$ Hollis Taylor)

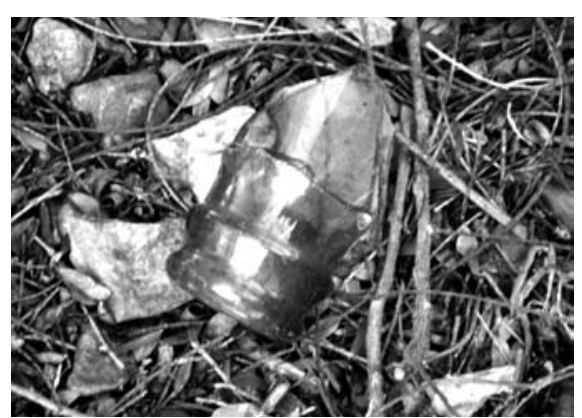

